\title{
BMJ Factors mediating HIV risk among open female sex workers in Europe: a systematic review and ecological analysis
}

\author{
Lucy Platt, ${ }^{1}$ Emma Jolley, ${ }^{1}$ Tim Rhodes, ${ }^{1}$ Vivian Hope, ${ }^{1,2}$ Alisher Latypov, ${ }^{3,4}$ \\ Lucy Reynolds, ${ }^{1}$ David Wilson ${ }^{5}$
}

To cite: Platt L, Jolley E, Rhodes T, et al. Factors mediating HIV risk among female sex workers in Europe: a systematic review and ecological analysis. BMJ Open 2013;3:e002836. doi:10.1136/bmjopen-2013002836

- Prepublication history and additional material for this paper is available online. To view these files please visit the journal online (http://dx.doi.org/10.1136/ bmjopen-2013-002836).

Received 5 March 2013 Revised 29 May 2013 Accepted 30 May 2013

${ }^{1}$ Centre for Research on Drugs and Health Behaviour, Faculty of Public Health and Policy, London School of Hygiene and Tropical Medicine, London, UK ${ }^{2}$ Centre for Infectious Disease Surveillance and Control, Public Health England, London, UK

${ }^{3}$ The Central Asia Program, Institute for European, Russian, and Eurasian Studies, George Washington University, Washington DC, USA

${ }^{4}$ Global Health Research Centre of Central Asia, Columbia University, New York, USA ${ }^{5}$ Global HIV/AIDS Programme, World Bank, Washington DC, USA

Correspondence to Dr Lucy Platt; lucy.platt@|shtm.ac.uk

\section{ABSTRACT}

Objectives: We reviewed the epidemiology of HIV and selected sexually transmitted infections (STIs) among female sex workers (FSWs) in WHO-defined Europe. There were three objectives: (1) to assess the prevalence of HIV and STIs (chlamydia, syphilis and gonorrhoea); (2) to describe structural and individuallevel risk factors associated with prevalence and (3) to examine the relationship between structural-level factors and national estimates of HIV prevalence among FSWs.

Design: A systematic search of published and unpublished literature measuring HIV/STIs and risk factors among FSWs, identified through electronic databases published since 2005. 'Best' estimates of HIV prevalence were calculated from the systematic review to provide national level estimates of HIV. Associations between HIV prevalence and selected structural-level indicators were assessed using linear regression models.

Studies reviewed: of the 1993 papers identified in the search, 73 peer-reviewed and grey literature documents were identified as meeting our criteria of which 63 papers provided unique estimates of HIV and STI prevalence and nine reported multivariate risk factors for HIV/STI among FSWs.

Results: HIV in Europe remains low among FSWs who do not inject drugs $(<1 \%)$, but STIs are high, particularly syphilis in the East and gonorrhoea. FSWs experience high levels of violence and structural risk factors associated with HIV, including lack of access to services and working on the street. Linear regression models showed HIV among FSWs to link with injecting drug use and imprisonment.

Conclusions: Findings show that HIV prevention interventions should be nested inside strategies that address the social welfare of sex workers, highlighting in turn the need to target the social determinants of health and inequality, including regarding access to services, experience of violence and migration. Future epidemiological and intervention studies of HIV among vulnerable populations need to better systematically delineate how microenvironmental and macroenvironmental factors combine to increase or reduce HIV/STI risk.

\section{ARTICLE SUMMARY}

\section{Article focus}

- A systematic review to identify and synthesise the prevalence estimates and risk factors for HIV and selected STIs among female sex workers (FSWs) in Europe.

- An ecological analysis to examine the relationship between structural-level risk factors and national estimates of HIV prevalence among FSWs in Europe.

Key messages

- The review shows how HIV remains low among FSWs who do not inject drugs. Injecting drugs is the primary individual-level risk factor for HIV among FSWs in Europe and HIV is highest in the East where prevalence among people who inject drugs is also high.

- FSWs are vulnerable to multiple forms of violence as well remain sexually vulnerable. Interventions need to address broader occupational and personal health concerns, including location where sex is sold, tackling violence, as well as low levels of condom and contraceptive use with non-paying partners.

- Targeted interventions need to be embedded within broader structural policies that improve the social welfare of sex workers and tackle social determinants of health, including improving access to services, reducing harms associated with enforcement and migration.

\section{INTRODUCTION}

While globally the number of new HIV infections has declined over the last decade, in Europe they have continued to increase. By 2012 there were over 1.5 million individual HIV case reports, with over half a million diagnoses reported in the Past 5 years. ${ }^{1}$ The epidemiology of HIV in Europe suggests a concentrated epidemic with the burden of HIV cases among men who have sex with men in the West and people who 


\section{ARTICLE SUMMARY}

Strengths and limitations of this study

- This review provides the most comprehensive estimates of HIV/STI estimates among FSWs in Europe to date, drawing on research published in four languages and is the first of its kind to delineate structural-level and individual-level risk factors.

- Multivariate analyses adjusted for a diverse range of confounders, making direct comparisons across studies difficult and precluding the use of meta-analysis.

- Findings of the review are dependent on the quality of the studies which were often variable and some studies were included that drew on small sample sizes.

- The small number of country reports prevented multivariate analysis in the ecological analysis and the descriptive linear nature of the relationships examined are unlikely to be a true representation of the complex multilevel relationship in play.

inject drugs (PWID) in the East. ${ }^{2}$ The epidemic in the East is fuelling the continuing increase in new HIV cases in Europe: between 2006 and 2011 an average of 273 cases per million people were recorded in the East compared with 74 and 11 in the West and Centre, respectively. ${ }^{3}$ While drug injecting is the main exposure category in the East, the number and proportion of cases linked with heterosexual exposure has increased within the last 5 years with over $60 \%$ of these cases among women. This emphasises the potential for concentrated HIV epidemics to become more generalised. ${ }^{4}$

A recent meta-analysis of HIV prevalence studies among female sex workers (FSWs) in low-income and middle-income countries suggested that FSWs-including from Europe (Georgia, Estonia and Ukraine)-had higher odds of HIV compared with all women of reproductive age. ${ }^{5}$ Evidence also suggests that the size of the female sex working population is correlated with countrywide HIV prevalence. ${ }^{6}$ Historically in West Europe, HIV prevalence among FSWs has remained low and European countries do not collate risk factor information concerning sex work as part of case reporting. Behavioural surveillance is also limited, usually collected through one-off surveys rather than ongoing or repeated surveillance at a national level. ${ }^{7}$ UNGASS indicators monitoring harms associated with sex work measure the proportion of sex workers (SWs) reached with an HIV prevention programme in the past 12 months, the proportion of FSWs and male SWs using a condom with their most recent client and the proportion of SW who are HIV positive. Problems with these indicators including lack of consistency in time frames used or definition of type sex act make drawing comparisons difficult across countries. ${ }^{8}$

Considering the growing epidemics of HIV in Europe, the continuing importance of heterosexual transmission in the West, emerging evidence of increased heterosexual transmission in the East and the significant overlap between sex work and drug injecting across the region, this study set out to review the epidemiology of HIV and selected sexually transmitted infections (STIs) among FSWs in WHO-defined Europe. ${ }^{4}{ }^{10}$ There is a growing body of research that substantiates relationships between structural factors and HIV vulnerability among SWs. ${ }^{11}{ }^{12}$ This literature highlights the importance of poverty as a major structural factor in risk and vulnerability related to drug use and sex work, particularly in countries experiencing large scale political and social transition. ${ }^{13}$ It also shows the effect of criminalisation of sex work disabling capacities for HIV prevention, for example, through the confiscation of condoms as evidence of prostitution ${ }^{12}{ }^{14}$ as well as indirectly through an increase in violence and mental health problems. ${ }^{15-17}$ However, HIV epidemiological research has tended towards the delineation of individual-level and proximal risk factors, neglecting the study of social determinants. ${ }^{18}$ This review therefore seeks to explore the extent to which recently published European evidence on HIV among FSWs measures structural risk factors. Our objectives were threefold: (1) to assess the prevalence and incidence of HIV and STIs (chlamydia, syphilis and gonorrhoea) among FSWs; (2) to describe risk factors associated with prevalence and incidence, delineating structural-level and individual-level factors and (3) to examine the relationship between structural-level factors and national estimates of HIV prevalence among FSWs.

\section{METHODS}

\section{Search strategy and selection criteria}

Two authors (LP and LR) systematically searched MEDLINE, EMBASE, Global Health, Social Science Citation Index, Popline and CINAHL for studies published from 2005 to 20 October 2011. To identify articles we combined five broad search themes with the Boolean operator "AND". The first theme, HIV, combined the Medical Subject Headings (MESH) terms "HIV" or "HIV infections" with the free word search for "HIV", "HIV" with "OR". The second theme STIs combined the MESH terms "Chlamydia" "Chlamydia infections", "Gonnorhea", "Syphilis" or "Treponema Pallidum" with free terms "Chlamydia Trachomatis", "Chlamydia", "C Trachomatis", "Treponema Pallidum", "T Pallidum", "syphilis", "Neisseria gonorrhoea", "N gonorrhoea", "Gonorrhoea", combined with "OR". The third theme, prevalence, incidence and risk factors, included the MESH terms "prevalence", "incidence", "risk", "factor analysis", "statistical", "regression analysis", "risk factors", "risk-taking" and "epidemiology" with the free words "prevalen*", "incidence", "risk*", "correlat*", "determinant*", "vulnerab*”, "regression", "risk", "(enhanc*adj3) transmission", "multivar*”, "(route*adj3 transmission)", "(factor*adj3 transmission)", "social norm*", "network", "socio-demographic", "socio-economic", "lifestyle" and "epidemiol*" with "OR". The fourth theme, geographic coverage, included the names of the countries in the region, as well as the free word terms "Europe*" and "Central Asia*" combined with "OR". The fifth theme 
combined the MESH terms "sex worker" and "prostitute" with the free words "sex work*" "prostitut*", "entertainment worker*", "(exchang* adj3 sex)", "(sell* adj3 sex)", "(sold* adj3 sex)", "(sex adj3 money)", "(transaction* adj3 sex)", "(commerc adj3 sex)", "(surviv* adj3 sex)", "(sex adj3 drug*)", "sex trade", "sex industry", "(sex* servic*)", " brothel*”, "red-light", "solicit*”, "bar girl*", "hostess*", " escort*", " masseu*" with "OR".

Reference lists of found articles were also searched and experts in the field consulted to identify other relevant studies. We conducted a systematic search of websites of research institutes, service providers and donor organisations working with SWs across the region. Conference abstracts from the International Conference on the Reduction of Drug-Related Harm were searched (2005-2010) and the International AIDS Conference (2006, 2008 and 2010). Where no HIV estimates were available we also looked further back and included estimates published up to 2000 .

\section{Study selection and eligibility}

We included reports written in English, Spanish, French and Russian published from 2000 to 2011 based on studies undertaken in WHO-defined Europe that reported rates on: HIV prevalence or incidence; syphilis, chlamydia and gonorrhoea. A FSW was defined as a woman who has ever exchanged sex for money, drugs or goods. Studies were included if they reported crude or adjusted associations.

Papers were excluded if they reported a sample size less than 50 (except in countries where limited data were available) had unclear sampling methods, or they contained no primary data, although the references were searched to gather primary studies not identified by the search. Papers not fitting the inclusion criteria were set aside to aid interpretation of the systematic review findings. Figure 1 summarises the papers searched and retained in the review. Following full-text review 73 peer-reviewed and grey literature documents were identified as meeting our criteria of which 63 papers provided unique estimates of HIV and STI prevalence and nine papers report multivariate or univariate ${ }^{2}$ risk factors for HIV/STI among FSWs.

One author (LP) extracted data on: survey year; recruitment location; sample size; geographical coverage; condom use with clients and non-paying partners; experience of violence from clients or police and injecting drug use. The heterogeneity of studies with regard to definitions of sex work, sampling strategy and geographical diversity precluded statistical meta-analysis. We therefore undertook a narrative synthesis and described prevalence of HIV and STIs, presenting adjusted and

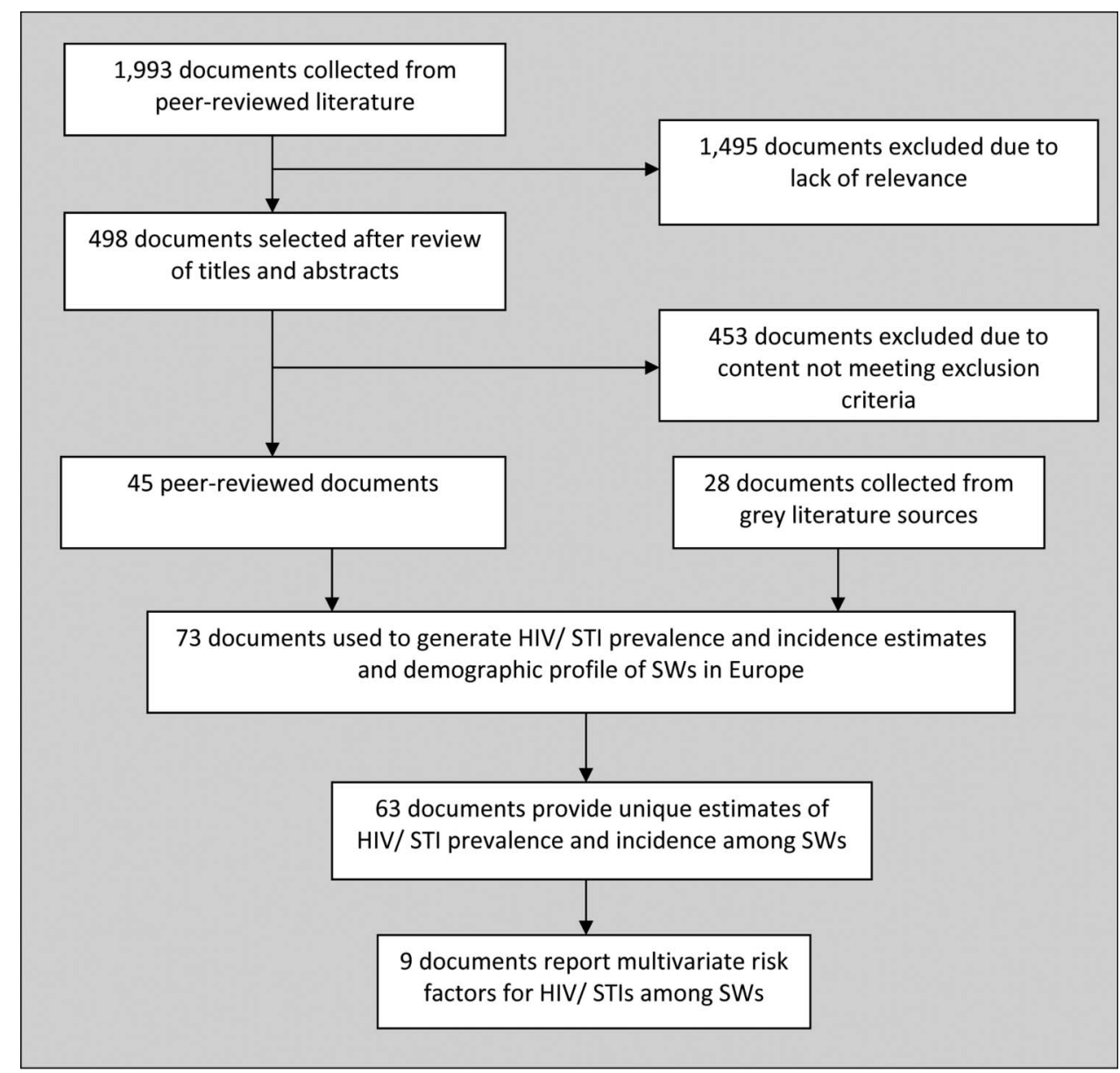

Figure 1 Flow chart of systematic review and study selection. 
unadjusted associations differentiating between structural and individual-level risk factors. 'Individual' level factors were defined as those endogenous to the individual and his or her agency or practices, whereas 'structural' factors were defined as those exogenous to the individual and/or indirectly linked to individual agency or practices. ${ }^{13} 19$ We therefore incorporate all forms of social and environmental factors potentially affecting risk within the category of 'structural'. We acknowledge at the outset unavoidable limits in distinguishing 'individual'-level from 'structural'-level factors given how these inevitably interplay, often indirectly and nonlinearly. ${ }^{18} 20$ Our review conformed to the PRISMA checklist for systematic reviews. ${ }^{21}$

\section{Ecological analysis}

Two authors (EJ and LP) independently assessed the quality of the studies reporting HIV prevalence estimates using a scoring system that graded the papers according to: sample size; wide geographic coverage; most recent study; population sampled and recruitment setting. We allocated up to three points each for most recent studies, population sampled, country coverage and for the range of settings sampled, and deducted one point for clinic only samples due to the potential for bias. ${ }^{22}$ 'Best' estimates were used to facilitate comparison of HIV prevalence estimates across the region. Linear regression models were used in order to assess the relationship between HIV prevalence and selected individual and structural indicators in an ecological analysis. Indicators were identified as important from the systematic review or where previous evidence has shown a relationship with HIV through ecological studies or multilevel modelling. These include: GINI coefficient providing an estimate of inequalities in wealth; female-to-male pay differential and the number of people imprisoned per 100000 population. ${ }^{23-25}$ The regression line was plotted on top of a two-way scatter graph plotting the HIV prevalence against the explanatory variable to examine the association visually. As well as allowing us to judge the existence of an association, in the event of an observed association it allowed us to judge the appropriateness of a straight line for representing the relationship or whether another type of relationship may exist between the outcome and explanatory variables. Separate regressions were run that focused on the central $50 \%$ of observations excluding extreme values that could unduly influence the linear regression model. All analyses used STATA V.12 (Stata Corp, College Station, Texas, USA).

\section{RESULTS}

\section{HIV among FSWs}

HIV prevalence among FSWs in West Europe is generally low, at $1 \%$ or less. ${ }^{8} 22$ 26-35 Prevalence was higher in Italy and Spain among street samples that included migrants and transgender SWs. ${ }^{29}{ }^{36-38}$ Prevalence of HIV is low in countries in Central Europe between $1 \%$ and $2 \% 83439-45$ and in East Europe consistently higher ranging between $2.5 \%$ and $8 \%$ in Azerbaijan (Baku), ${ }^{46} 47$ 4.6\% in Moldova $(\text { Chisinau })^{47}$ and $7.6 \%$ in Estonia (Tallinn). ${ }^{48}$ A lower prevalence was reported in Georgia and Armenia at less than $2 \%^{34}{ }^{49}$ and $0 \%$ in Lithuania and Belarus. ${ }^{34} 50$ A higher prevalence was reported in 2009 in Minsk (Belarus) of $6.4 \%$, where $15.5 \%$ of the sample reported injecting. ${ }^{51}$ In both the Russian Federation and Ukraine, prevalence varied significantly by city ranging from $2 \%$ to $62 \%$ in Tomsk and Togliatti, Russia and between zero in Uzhgorod, Kharkov and Chernitz and 42\% in Donetsk, Ukraine. ${ }^{52-54}$ In the Netherlands, HIV prevalence was reported at $3.8 \%$ overall but far higher among women with a history of injecting drug use $(13.6 \%)$ compared with those without $(1.5 \%) .{ }^{38}$ In Spain, Portugal and the UK small samples of FSWs suggested higher HIV prevalence ranging between $4 \%$ and $24 \%$ among heroin or crack users. ${ }^{26} 36{ }^{55}$ However, in the East in Azerbaijan (Baku), Moldova (Chisinau) and Estonia (Tallinn) high HIV prevalence was reported $(2.5-8 \%)$ despite relatively lower levels of drug injecting $(<10 \%) \cdot{ }^{46-48}$ All studies are presented in table 1 . Where multiple estimates are available the range of estimates are presented alongside the 'best' estimate.

\section{Syphilis}

Table 2 summarises prevalence of STIs. Prevalence of syphilis is highest among samples of FSWs in the East. Across the region, prevalence of syphilis is higher than HIV with the exception of Ukraine, although this varied considerably at a city level. ${ }^{53}$ In 2001, a high prevalence of syphilis was found among a group of migrant street SWs in Italy $(12 \%)$, these cases were among migrants from Eastern Europe (countries not specified) and infection was attributed to past infection at home. ${ }^{57}$ In Greece there were no cases of HIV among off-street working FSWs in Athens, but a high prevalence of syphilis was observed $(18 \%) .{ }^{32}$ Among this sample $20 \%$ were migrants from East Europe but prevalence did not differ by country of origin. In Russia and Moldova the data suggest a concurrent epidemic of syphilis and HIV among FSWs, with all such study samples including FSWs who inject drugs. ${ }^{4785}$

\section{Chlamydia and gonorrhoea}

Across West Europe, prevalence of chlamydia remains low at under 7\% among FSWs. Two older studies in Italy suggested a prevalence of $14 \%$ of chlamydia among migrant FSWs ${ }^{57} 87$ and a high prevalence $(45 \%)$ among off-street as well as street working FSWs in three cities in Serbia (Kosova) among samples recruited from STI clinics. ${ }^{41}$ Prevalence of gonorrhoea is reported at $5 \%$ or less across the region, with the exception of Georgia $(12-18 \%)$ and a prevalence of chlamydia of just over $20 \% .^{73}$ 
Table 1 Prevalence of HIV, injecting drugs, violence and condom use among FSWs in Europe

\begin{tabular}{|c|c|c|c|c|c|c|c|c|c|c|c|c|c|}
\hline \multirow[b]{2}{*}{ Country } & \multirow[b]{2}{*}{ Area } & \multirow[b]{2}{*}{ Population sampled } & \multirow[b]{2}{*}{ Survey year } & \multicolumn{2}{|c|}{$\begin{array}{l}\text { Studies } \\
\mathrm{n}\end{array}$} & \multicolumn{2}{|c|}{$\begin{array}{l}\text { Injecting drug } \\
\text { use }\end{array}$} & \multicolumn{2}{|l|}{ HIV (\%) } & \multirow[b]{2}{*}{ Violence } & \multicolumn{2}{|c|}{ Non-condom use } & \multirow[b]{2}{*}{ Reference } \\
\hline & & & & $\overline{\#}$ & $\mathbf{n}$ & Range & Best & Range & Best & & Clients & Other* & \\
\hline \multicolumn{14}{|l|}{ West } \\
\hline Austria & 3 & STI clinics & 2002 & 1 & 1184 & & $3 \%$ & $1-4 \dagger$ & 2 & & & & 56 \\
\hline Belgium & 1 & $\mathrm{~N} / \mathrm{A}$ & 2008 & 1 & 1016 & $\mathrm{~N} / \mathrm{A}$ & & & 0.3 & & & & 8 \\
\hline France & 1 & Chinese sex workers & 2008 & 1 & 46 & $\mathrm{~N} / \mathrm{A}$ & & & $0(0)$ & & & & 8 \\
\hline Germany & Nat & STI/VCT/private clinics & 2002; 2010-2011 & 2 & $290-3380$ & & $3 \%$ & $0.2-0.3$ & 0.2 & & & & 835 \\
\hline Greece & 1 & STI clinic (migrants) & 2005 & 1 & 299 & & 0 & & $0(0)$ & & & & 32 \\
\hline Italy & 4 & Street SWs at STI clinics & $1992-2008$ & 4 & $118-558$ & & $9 \%$ & $1.6-8$ & 7 & & $12-16 \%$ & $84 \%^{7}$ & 57583137 \\
\hline The Netherlands & 2 & Street and off street ${ }^{+}$ & 2002-2005 & 2 & 399-1018 & & $16 \%$ & $0.5-13.6$ & 3.8 & & $11 \%$ & $89 \% 8$ & 5638 \\
\hline Norway & 1 & Specialist STI clinic (MSWs) & 2008 & 1 & 746 & $\mathrm{~N} / \mathrm{A}$ & & & 1 & & & & 8 \\
\hline Portugal & 1 & Street (migrants) & 2000-2001 & 1 & 96 & $50-60 \%$ & $55 \%$ & & 14 & & & & 59 \\
\hline Spain & 4 & Street (migrants) & $1998-2004$ & 5 & $301-3149$ & $1 \%$ & $1 \%$ & $0.8-4.5$ & $3 \% \neq$ & & $<5 \%$ & $92 \%^{9}$ & 2926603328 \\
\hline Sweden & $N / A$ & Prison & $2006-2007$ & 1 & 45 & $\mathrm{~N} / \mathrm{A}$ & & & 2.2 & & & & 8 \\
\hline UK & 5 & Street/off-street (migrants) & $1986-2009$ & 5 & $25-268$ & $4-96 \%$ & $4 \%$ & $0-24$ & 1 & $30.2 \%{ }^{1}$ & $<1 \%$ & $70 \%{ }^{10}$ & 59552261 \\
\hline \multicolumn{14}{|c|}{ 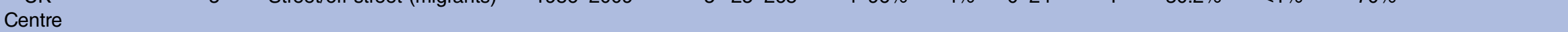 } \\
\hline Bosnia and Herzeg & 1 & $\mathrm{~N} / \mathrm{A}$ & 2007 & 1 & 42 & N/A & & & $0(0)$ & & & & 45 \\
\hline Bulgaria & 3 & Street/off-street§ & 2005,2008 & 2 & $799-874$ & & $2 \%$ & $0.6-1.0$ & 0.6 & & & & 6263 \\
\hline Croatia & 1 & NGO & 2003-2005 & 1 & 43 & & $36 \%$ & & 2 & $30-53 \%{ }^{2}$ & $<5 \%{ }^{11}$ & & 42 \\
\hline Czech Republic & 2 & Street & $1999-2000$ & 2 & $585-797$ & $10 \%$ & $10 \%$ & $0.1-0.7 \%$ & 0.7 & & & & 6456 \\
\hline Israel & 2 & Off-street, illegal migrants & $2008 \eta$ & 2 & $43-300$ & & $0.1 \%$ & $0-0.3$ & 0.3 & & $<5 \%{ }^{12}$ & & 3027 \\
\hline Hungary & $\mathrm{N} / \mathrm{A}$ & Mobile clinic & 2006 & 1 & 500 & $\mathrm{~N} / \mathrm{A}$ & & & $0(0)$ & & & & 8 \\
\hline Macedonia & Multi & N/A & 2005-2007 & 3 & $48-67$ & & $7 \%$ & $0-1.9$ & $1 \ddagger$ & & & & 44 \\
\hline Montenegro & $\mathrm{N} / \mathrm{A}$ & $N / A^{* *}$ & 2007 & 1 & 133 & $\mathrm{~N} / \mathrm{A}$ & & & 0.8 & & & & 65 \\
\hline Poland & 2 & Clinic and community & $2002-2005$ & 2 & $250-650$ & & $2 \%$ & $0-2$ & 1 & & & & 56 \\
\hline Romania & 1 & Street & 2006 & 1 & 204 & & $22 \%$ & & 1 & $46 \%^{3}$ & $35 \%$ & $52-60 \%^{12}$ & 8 \\
\hline Serbia & 1 & Street/off-street†† & 2010 & 1 & 250 & & $27 \%$ & & 1 & & & & 66 \\
\hline Serbia (Kosova) & 1 & Street/off street (migrants $\ddagger$ ) & 2006 & 1 & 157 & & $1 \%$ & & $0(0)$ & $16 \%^{3}$ & $38 \%$ & $45 \%^{13}$ & 67 \\
\hline Turkey & 3 & Unregistered FSWs & $2006-2007$ & 1 & 252 & & $2 \%$ & & 0.8 & & & & 68 \\
\hline \multicolumn{14}{|l|}{ East } \\
\hline Albania & 1 & Street/bars & 2008 & 1 & 90 & & $0.2 \%$ & & 1.1 & $30 \% 4$ & & & 69 \\
\hline Armenia & Multi & VCT/STI clinics & $2000-2007$ & 3 & $168-250$ & $0.4-1.2 \%$ & $1 \%$ & $0.4-1.2 \%$ & 0.4 & & $33 \%{ }^{14}$ & & 567071 \\
\hline Azerbaijan & 2 & Street/off-street & 2003-2008 & 2 & $200-300$ & & $1 \%$ & $2.5-8.5$ & 3 & & $78 \%$ & $86 \%{ }^{1}$ & 4647 \\
\hline Belarus & 1 & Street/STI clinics & 2004-2009 & 3 & $208-481$ & $15.50 \%$ & $15 \%$ & $0-6.4$ & $3 \ddagger$ & & & & 5672 \\
\hline Estonia & 1 & Street/off-street (RDS) & 2005-2006 & 1 & 227 & & $7 \%$ & & 8 & & $25 \%{ }^{15}$ & & 48 \\
\hline Georgia & 2 & Street/off-street (TLS) & 2002-2009 & 7 & $114-160$ & $1-6 \%$ & $6 \%$ & $0-1.9$ & 1 & $13-29 \%^{5}$ & $10 \%{ }^{12}$ & & 7349 \\
\hline Latvia & 2 & & 2002-2004 & 2 & $92-93$ & & $53 \%$ & $16-18$ & 18 & & & & 56 \\
\hline Lithuania & 2 & Street/AIDS centre & $2005-2007$ & 2 & $67-101$ & & $1 \%$ & $0 \%(0)$ & $0(0)$ & & $8 \%{ }^{10}$ & & 5674 \\
\hline Moldova & 4 & Harm reduction and RDS & 2001-2009 & 4 & $151-300$ & & $11 \%$ & $2.9-8.5$ & 6 & $53.4 \%{ }^{6}$ & $17 \%{ }^{10}$ & & 4775 \\
\hline
\end{tabular}


Table 1 Continued

\begin{tabular}{|c|c|c|c|c|c|c|c|c|c|c|c|c|c|}
\hline \multirow[b]{2}{*}{ Country } & \multirow[b]{2}{*}{ Area } & \multirow[b]{2}{*}{ Population sampled } & \multirow[b]{2}{*}{ Survey year } & \multicolumn{2}{|c|}{$\begin{array}{l}\text { Studies } \\
\text { n }\end{array}$} & \multicolumn{2}{|c|}{$\begin{array}{l}\text { Injecting drug } \\
\text { use }\end{array}$} & \multicolumn{2}{|l|}{ HIV (\%) } & \multirow[b]{2}{*}{ Violence } & \multicolumn{2}{|c|}{ Non-condom use } & \multirow[b]{2}{*}{ Reference } \\
\hline & & & & $\overline{\#}$ & $\mathbf{n}$ & Range & Best & Range & Best & & Clients & Other* & \\
\hline Russian Fed & 17 & Street STI clinics & 2001-2009 & 9 & $66-1777$ & $5-100 \%$ & $35 \%$ & $2-62.1$ & $8 \ddagger$ & $20-76 \%^{1}$ & $0-32 \%^{10}$ & & 475476567778 \\
\hline Ukraine & Multi & Street & 2002-2009 & 3 & $646-3248$ & $15-24 \%$ & $24 \%$ & $12.9-20$ & $13 \ddagger$ & & $10 \%$ & & 567980 \\
\hline Kazakhstan & 6 & Community & 2005-2008 & 6 & $1960-3903$ & $10-18 \%$ & $12 \%$ & $0.1-2.5$ & $2 \ddagger$ & & $20 \%$ & $20-50 \%{ }^{10}$ & 8156 \\
\hline Kyrgyzstan & 1 & & 2006 & 4 & 352 & $0.4-5 \%$ & $5 \%$ & $1.3-1.9$ & $1 \neq$ & & $<20 \%$ & $20-50 \%{ }^{10}$ & 81 \\
\hline Tajikistan & $5^{\beta}$ & & $2006-2008$ & 4 & 1200 & $0.3-2 \%$ & $13 \%$ & $1.6-3.7$ & $4 \ddagger$ & & $30 \%{ }^{10}$ & & \\
\hline Uzbekistan & Nat & FSWs and MSWs & 2003-2007 & 3 & $407-2000$ & $0-100 \%$ & $7 \%$ & $4.7-58.5$ & 5 & & & & 828384 \\
\hline
\end{tabular}

${ }^{*}$ Other refers to all non-paying partners. Seven never using condoms; 8 inconsistent use with steady partner; nine not always using condom for vaginal sex; 10 no condom use at last vaginal sex; 11 no condom use at last commercial sex; 12 inconsistent; 13 never using condoms in last 30 days; 14 inconsistent condom use for vaginal sex in last 7 days and 15 inconsistent for vaginal and anal sex.

†Range provided as sample stratified by FSWs who are registered, illegal FSWs, unregistered FSW and FSWs recruited from STI clinic.

†Weighted mean.

(1) Physical or sexual violence; (2) physical violence; (3) forced to have sex; (4) ever forced to have sex; (5) experience physical or sexual violence during last year, in Batumi $13 \%$ refers to physical violence only; (6) experienced violence or been threatened.

§IIncludes $16 \%$ MSWs +Includes $12.5 \%$ Transgender SWs.

IDate of publication, no data available on year of study.

**Includes MSWs $(n=14)$. In Norway and Uzbekistan \% MSW in sample not specified.

t†lncludes MSWs (22\%) and Transsexuals (16\%).

$\neq \neq$ Mostly migrants from Bulgaria, Albania, Moldova, Ukraine.

FSW, female sex worker; MSW, male sex worker; N/A, not available; Nat, National $\beta$ refers to region; RDS, respondent driven sampling; STI, sexually transmitted infection; TLS, time location sampling; VCT, Voluntary Counselling and Testing. 
Table 2 Prevalence of HIV, Syphilis, Chlamydia and Gonorrhoea among samples of FSWs in Europe

\begin{tabular}{|c|c|c|c|c|c|c|c|c|c|}
\hline Country & City & Population & Year & $\mathbf{n}$ & Syphilis (\%)* & $\begin{array}{l}\text { Chlamydia } \\
(\%)\end{array}$ & $\begin{array}{l}\text { Gonorrhoea } \\
(\%)\end{array}$ & $\begin{array}{l}\text { HIV } \\
(\%)\end{array}$ & Reference \\
\hline \multicolumn{10}{|l|}{ West } \\
\hline Belgium & Ghent & Off-street ( $40 \%$ migrants) & 1998-2003 & 950 & & 7 & & & 86 \\
\hline \multirow[t]{2}{*}{ Italy } & Bologna & FSW inc migrants & 1995-1999 & 558 & 12 & 6 & 1 & 2 & 57 \\
\hline & Brescia & Migrant FSWs & $1998-2000$ & 101 & & 14 & & & 87 \\
\hline Greece & Athens & STI clinic (migrants) & 2005 & 299 & 18 & & & 0 & 32 \\
\hline \multirow[t]{2}{*}{ Spain } & Madrid & FSW inc migrants & 1998-2003 & 66 & 3 & & & 0 & 29 \\
\hline & Barcelona & FSWs (street) & 2002-2003 & 301 & & 5 & 4 & & 33 \\
\hline UK & London & $\begin{array}{l}\text { Street/off-street } \\
\text { (migrants) }\end{array}$ & 2007-2008 & 268 & 2 & 4 & 2 & 1 & 22 \\
\hline \multicolumn{10}{|l|}{ Centre } \\
\hline Bulgaria & 8 cities & Street/off-street† & 2005 & 799 & 10 & & & 1 & 63 \\
\hline Israel & Tel Aviv & FSWs (off-street) & & 300 & & 6 & 5 & & 30 \\
\hline Serbia & Belgrade & FSW, MSW, Trans & 2010 & 250 & 4 & & & 1 & 66 \\
\hline Serbia (Kosova) & $\begin{array}{l}\text { Ferizaj, Urosevac, } \\
\text { Prizren }\end{array}$ & $\begin{array}{l}\text { Migrant FSWs (street/ } \\
\text { indoor) }\end{array}$ & 2006 & 153 & & 45 & & & 41 \\
\hline \multirow[t]{2}{*}{ Turkey } & Ankara, Istanbul, Izmir & Unregistered FSWs & 2006-2007 & 252 & 7.5 & 1.2 & 2.8 & 0.8 & 68 \\
\hline & Gazaniantep & Registered FSWs & $1997-1998$ & 92 & & 5 & & & 88 \\
\hline \multicolumn{10}{|l|}{ East } \\
\hline Albania & Tirana & Street/bar & 2011 & 90 & 6 & & & 1.1 & 69 \\
\hline Azerbaijan & Baku, Gandja, Sumgait & Street/off-street & 2001 & 200 & 9 & & & 3 & 47 \\
\hline Kyrgyzstan & Bishkek, Osh & & 2006 & 352 & 34.9 & & & 1.4 & 81 \\
\hline Georgia & Tbilisi, Batumi & Street/off-street (TLS) & 2002-2006 & 160 & 34.1 & $22-23$ & $12-18$ & 0.4 & 73 \\
\hline \multirow[t]{3}{*}{ Russia } & Moscow & Street (5\% PWID) & 2001 & 147 & 26 & & & 14 & 47 \\
\hline & Ekaterinburg & Street (27\% PWID) & 2001 & 151 & 22 & & & 15 & 47 \\
\hline & $\begin{array}{l}\text { Moscow, Volgograd, } \\
\text { Barnaul }\end{array}$ & Street (100\% PWID) & 2003 & 98 & 16 & & & 7 & 85 \\
\hline Ukraine & 15 cities & Street (24\% PWID) & 2009 & 2278 & 4.4 & & & 12. 9 & 53 \\
\hline
\end{tabular}

${ }^{*}$ Refers to prevalence of antibodies to Treponema pallidum and detect current and past infection with syphilis.

†Includes 16\% MSWs TLS.

FSW, female sex worker; PWID, people who inject drugs; STI, sexually transmitted disease; TLS,Time Location Sampling. 
Risk factors associated with HIV/STls

Individual risk factors

Studies conducted in Ukraine and Uzbekistan examining risk factors for HIV among FSWs show more evidence of increased risk associated with injecting drug use. $^{53} 8283$ Among FSWs currently injecting drugs, the risk of HIV is higher among those who reported selling sex for drugs and injecting daily, ${ }^{83}$ and among those injecting home-made drugs in the Russian Federation. ${ }^{76}$ In Ukraine, having a sex partner who also injects drugs was associated with increased risk of HIV. ${ }^{53}$ Six studies reported associations with sexual risk behaviours including: unprotected sex with clients; numbers of clients; existence of a non-paying partner and sex with someone living with HIV. ${ }^{22} 3035485383$ One study reported an association between type of contraceptive used and found that those relying on condoms as a main form of contraceptive had reduced odds of HIV compared with those that did not (figure 2). ${ }^{35}$

\section{Structural risk factors}

Four studies found increased odds of HIV associated with working on the street compared with other off-street venues. ${ }^{354853} 83$ Four studies reported a protective effect of attendance at an HIV prevention programme ${ }^{35} 5388$ or contact with an outreach team ${ }^{22}$ that included STI treatments. However, in Tashkent there was no protective effect from attendance at a needle or syringe programme. ${ }^{83}$ Two studies that analysed associations between migration and HIV adjusting for confounders suggested no difference in risk between local and migrant FSWs. $^{22} 53$ Other factors relating to migration were important risk factors for HIV including language skills of migrants and access to health insurance (figure 3). ${ }^{35}$

\section{Violence}

We identified eight quantitative studies that reported experience of violence among FSWs across Europe. Definitions of violence varied, encompassing incidences of enacted physical, sexual as well as threatened violence. Incidences of violence were consistently high across the region, with more than $20 \%$ of samples reporting either physical or sexual violence in the last 12 months and some estimates reaching $76 \%$ in Russia. $^{47}$ In Serbia (Kosova) $16 \%$ of FSWs reported being forced to have sex against their will in the last

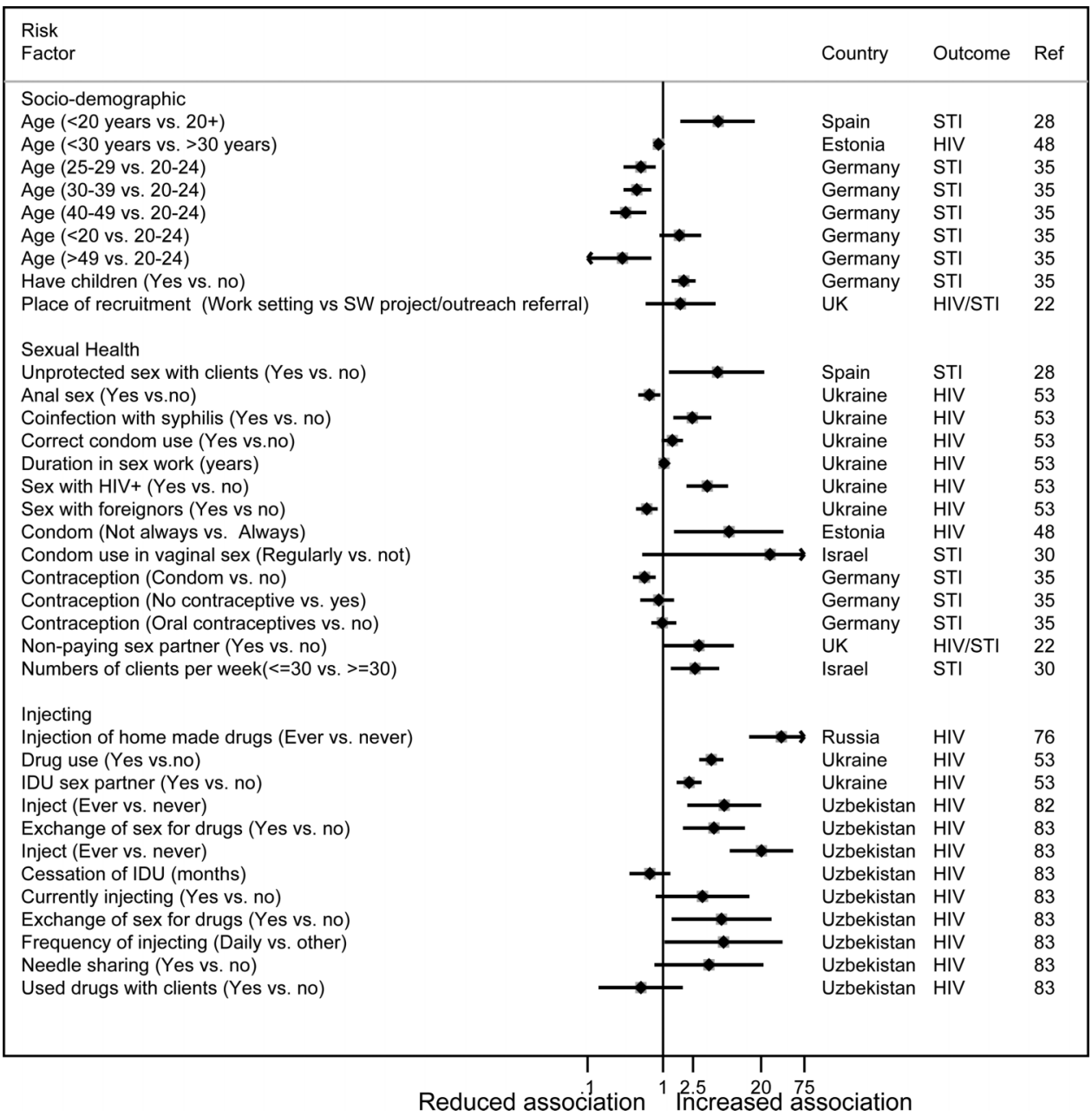

Figure 2 Individual level risk factors associated with HIV/STIs among FSWs in Europe. 


\begin{tabular}{|c|c|c|c|c|}
\hline \multicolumn{2}{|l|}{$\begin{array}{l}\text { Risk } \\
\text { Factor }\end{array}$} & Country & Outcome & Ref \\
\hline Health Service & & & & \\
\hline Contact with prevention programme (No vs. yes) & $\rightarrow$ & Ukraine & HIV & 53 \\
\hline No of STI treatments (More v. less) & $\rightarrow$ & Uzbekistan & hIV & 83 \\
\hline Participation at NSEP (No vs. yes) & & Uzbekistan & HIV & 83 \\
\hline First time at clinic (Yes vs. no) & $+\infty$ & Germany & STI & 35 \\
\hline Visit from outreach worker (Yes vs. no) & $\rightarrow$ & UK & HIV/STI & 22 \\
\hline Migration & & & & \\
\hline Migrant status (Migrant vs. Local) & & Ukraine & HIV & 53 \\
\hline Health insurance (No vs. yes) & $\rightarrow$ & Germany & STI & 35 \\
\hline Germany language (Very poor/none vs. fluent/medium) & $\rightarrow$ & Germany & STI & 35 \\
\hline Migrant status (EE/FSU vs. UK-born) & & UK & HIV/STI & 22 \\
\hline Socio-demographic & & & & \\
\hline Activities outside sex work (Nothing vs. study) & $\infty$ & Ukraine & HIV & 53 \\
\hline Activities outside sex work (Nothing vs. permanent job) & - & Ukraine & HIV & 53 \\
\hline Network size $(>5$ vs. $<5)$ & & Estonia & HIV & 48 \\
\hline Location & & & & \\
\hline Location of sex work (Street vs. internet) & $\leftarrow$ & Ukraine & HIV & 53 \\
\hline Location (Brothels/managed appartments vs. self employed) & $\longrightarrow$ & Estonia & HIV & 48 \\
\hline Location (Street vs. self employed) & & Estonia & HIV & 48 \\
\hline Location (Street vs. Off-street) & $\longrightarrow$ & Uzbekistan & ר HIV & 83 \\
\hline Location of sex work (Brothel vs. no) & & Germany & STI & 35 \\
\hline Location of sex work (Street vs. no) & $\rightarrow$ & Germany & STI & 35 \\
\hline Location of sex work (Bars/strip clubs vs. no) & $\leftarrow$ & Germany & STI & 35 \\
\hline Location of sex work (Internet vs. no) & & Germany & STI & 35 \\
\hline Location of sex work (Flat vs. no) & & Germany & STI & 35 \\
\hline
\end{tabular}

Figure 3 Structural level risk factors associated with HIV/STIs among FSWs in Europe.

12 months. ${ }^{41}$ In Armenia, $30 \%$ of street SWs reported a lifetime experience of forced $\operatorname{sex}^{89}$ and $54 \%$ had experienced violence or been threatened by clients in Moldova. ${ }^{47}$ Younger SWs may be more vulnerable to violence; in Romania $46 \%$ of a sample of FSWs (aged 16-24 years) had been forced to have sex in the last 12 months. $^{90}$

\section{Condom use}

Condom use with clients was consistently higher among FSWs in West Europe $(<17 \%$ reported inconsistent condom use with clients) compared with those in the East (0-78\% inconsistent use) and Central European countries (ranging between 5\% and 38\% inconsistent condom use). Across all the countries condom use with non-paying partners was less common than with clients (table 1).

\section{Ecological analysis}

Best HIV prevalence estimates were calculated for 39 countries across Europe, with a median prevalence of $1 \%$ (IQR 0-8\%), and the highest prevalence (18\%) reported in Latvia. Across the region the median prevalence of injecting was $6.5 \%$, with the countries of highest prevalence of injecting in Portugal, Latvia and
Croatia (see table 1). Overall there was a higher prevalence of injecting in the East, and Centre than West. The median GINI coefficient was 0.34 , with little difference across the subregions. Russia and Macedonia have the highest GINI coefficient, but there is little difference by subregion. The median female-to-male pay differential was 0.6 ; countries with the greatest pay differential include Norway, Moldova and Hungary. The median number of people imprisoned per 100000 population is 137, with far higher numbers in the East compared with the other subregions. Kyrgyzstan, Ukraine, Kazakhstan, Belarus and Russia all have prison populations greater than 390/100 000. Across the region, Russia, Slovenia, Spain and Germany have the fewest number of SW targeted services $(<0.2 / 1000 \mathrm{FSWs})$. Services were defined to include a wide range of sexual health, social support and legal services and exclude standard STI clinics and health services that treat non-sex working populations. Finland, Norway and Luxembourg have the largest number $(>2.8)$. Structural indicators are summarised in the web appendix (table S3).

There is a clear linear relationship between HIV prevalence among FSWs and increasing levels of injecting drug use across Europe. There is some evidence to suggest that countries with a higher GINI coefficient 
have higher HIV prevalence among FSWs. The graphical distribution of gender pay differential and HIV prevalence among FSWs suggests counter-intuitively that HIV prevalence increases as pay differentials decrease. Prevalence of HIV among FSWs increased with numbers in prison per 100000 population. There was no relationship between HIV and numbers of SW-specific services (see figure 4). Only injecting drug use (coefficient $=$ $0.22,95 \%$ CI 0.14 to $0.30, \mathrm{R}^{2}=0.5, \mathrm{p} \leq 0.001$ ) and prison population (coefficient $=0.0001,95 \%$ CI 0.00003 to $0.0002, \mathrm{R}^{2}=0.2, \mathrm{p}=0.01$, data not shown) were statistically associated with HIV prevalence univariately in a linear regression model.

\section{DISCUSSION}

This systematic review finds that HIV in Europe remains low among FSWs who do not inject drugs $(<1 \%)$ and that drug injecting is the primary individual-level risk factor for HIV among FSWs. HIV prevalence among FSWs is highest in the East where prevalence is also highest among PWID. Within high HIV prevalence countries, such as Russia and Ukraine, there is a wide variation in HIV among FSWs at a city level.

While evidence suggests that injecting risk practices are the main transmission route of HIV among FSWs who inject drugs, ${ }^{91}$ it is important to note evidence suggesting that sex work is associated with HIV seroconversion among women who inject drugs. ${ }^{92} 93$ Our findings underscore the importance of addressing sexual and not only injecting risk practices among FSWs who inject. In Estonia, for example, HIV was not associated with drug injecting among FSWs who had correspondingly lower hepatitis $\mathrm{C}$ prevalence, suggesting less risky injecting practices. ${ }^{48} \mathrm{~A}$ similar pattern has been observed in Russia: with reduced odds of HCV among FSWs who inject drugs, but increased odds of syphilis pointing to the potential for sexual transmission. ${ }^{54}$ In addition, prevalence of gonorrhoea is between 10 and 100 times higher than in general population samples ${ }^{94}$ suggesting that FSWs remain sexually vulnerable.

In all countries, where estimates were given, prevalence of violence was higher than HIV. Emerging evidence shows how violence may increase risk of HIV, for example, by reducing self esteem and ability to negotiate safer practices for fear of further violence, increasing drug use to manage the stress of violence or forced relocation of sex work to less familiar or safe areas. ${ }^{14} 95-97$ Legislation regulating sex work is a key structural determinant of violence and HIV risk. The practice of criminalising activities related to sex work can reduce opportunities for communication between FSWs and often resulting in the concentration of sex work onto the street. ${ }^{98}{ }^{99}$ Several studies showed increased risk of HIV associated with working on the street $t^{35} 485383$ and other evidence has documented increased risk of violence among street workers compared with off-street workers. ${ }^{100}$ Legislation may also influence community attitudes towards SWs with criminalisation of sex work reinforcing negative attitudes and violence towards SWs and hinder the implementation of targeted services. ${ }^{101} 102$ The ecological analysis showed evidence of a clear linear relationship between increasing numbers of people imprisoned and increased HIV prevalence
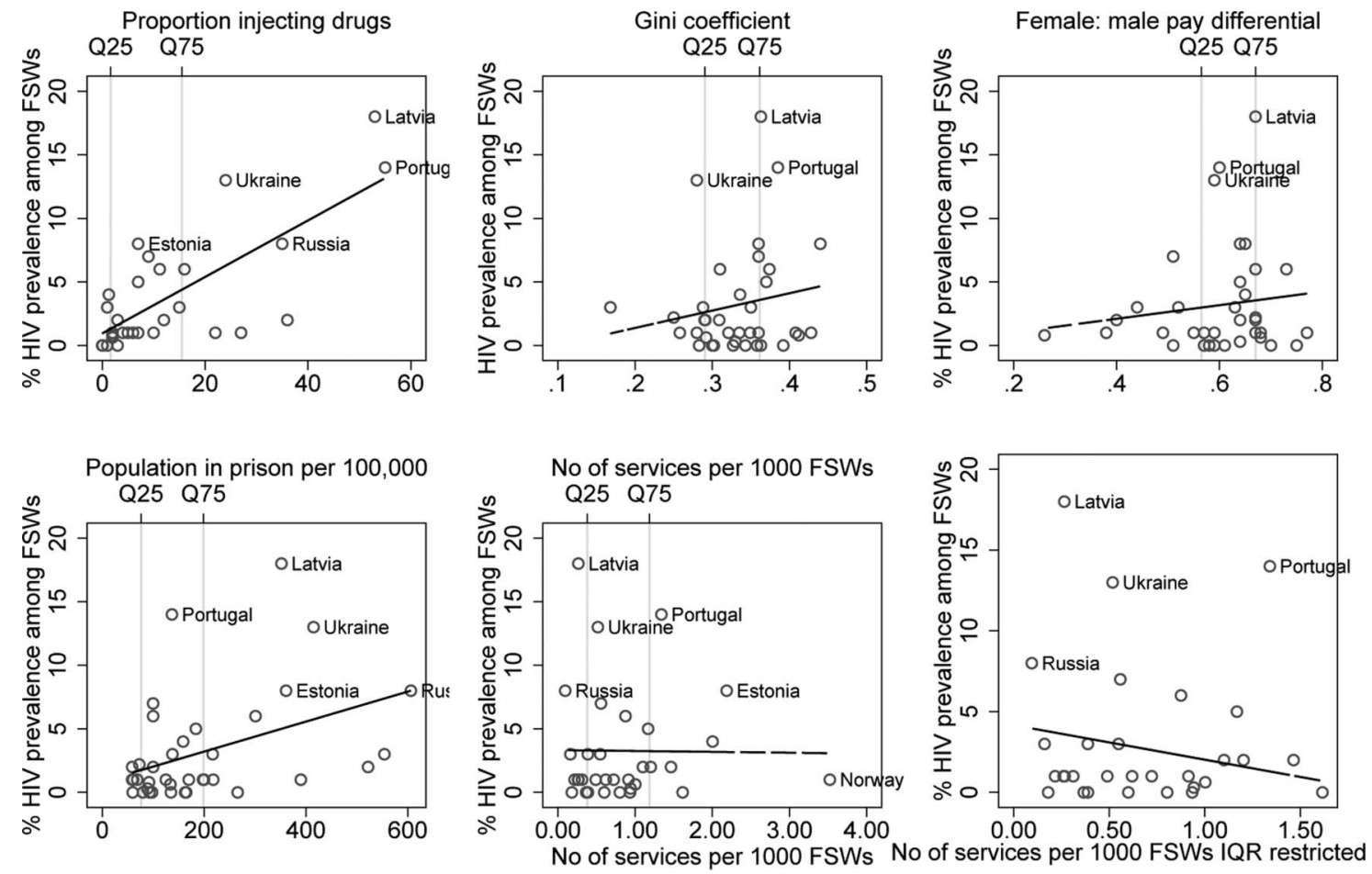

Figure 4 Linear association between structural indicators and HIV prevalence among female sex workers. 
among FSWs. Prison, an effect of criminalisation of drug use and sex work, is well documented as an HIV risk environment among PWID ${ }^{103} 104$ and other research has shown that criminalisation and enforcement-based approaches towards sex work can increase risk of both physical and sexual violence against SWs, ${ }^{14} 99105$ as well as risk of STIs. ${ }^{12} 85$ Despite this there is little quantitative data examining the effect of policing practices or enforcement on experience of violence, HIV or other adverse health outcomes among SWs. ${ }^{99}$

Our ecological analysis found increased HIV prevalence to link with a higher GINI coefficient, while research elsewhere has also documented how inequalities in wealth may correlate with increased prevalence of HIV, gender inequalities, overall lower life expectancy and illegal drug use. ${ }^{106}$ The association we found between increased HIV prevalence and decreased gender pay differential is counter-intuitive, but may in part be explained by a relationship between the countries of the East with high burdens of HIV and lingering equal-labour, equal-wage policies in the public sector that were originally put in place during the time of the Soviet Union. These data are derived from the ratio of the female-to-male non-agricultural wages, which may not be appropriate in highly agricultural economies in parts of Central and Eastern Europe and Central Asia. ${ }^{107}$ Findings from the systematic review, suggest that while increased risk of HIV is not associated with originating from another country, structural factors such as lack of health insurance or language skills may. Policy changes including the removal of migration policies restricting migrants' use of health services need to be removed to increase access to services alongside the provision of translated materials and interpreters to facilitate communication.

We found that the presence of services for SWs may be associated with reduced HIV prevalence at certain levels, but when prevalence is higher this relationship becomes less clear. When restricting the analysis to the mid-range number of services, HIV prevalence appears to decline as the number of SW-specific services increase. The scatter of data points around the regression lines are not very evenly distributed, while a relationship may exist between the variables it may not be best represented by a straight line. There is a wealth of evidence globally showing the positive impact of specialist services in reducing risk of HIV and STIs among FSWs. ${ }^{12} 108$ Countries reporting the fewest number of services include Russia and Germany, with Germany reporting very low prevalence of HIV among FSWs (0.2\%) compared with Russia (8\%). Our estimate of services does not take into account the type of services available or general STI clinics. Evidence from Russia suggests that interventions among SWs who inject focus almost exclusively on preventing viral transmission linked to the shared use of injecting equipment, there is also some evidence to suggest male PWID in Russia resent women attending harm reduction services, which may further restrict attendance by FSWs. ${ }^{109}$ In Germany not only is sex work legal, SWs have well-organised advocacy groups, but heath authorities are required to conduct outreach to vulnerable populations to engage them in services, factors which will create a very different context in which sex work operates and women access services.

\section{LIMITATIONS}

By limiting the search to literature published in four European languages we may have missed key studies. All estimates included in the review were rated highly with the exception of Sweden, Bosnia and Herzegovinia and Macedonia. The time frame of search was extended in order to identify better-quality estimates for Italy, Spain, Moldova and Portugal. This increased the range of field work within which data are presented back to 1998. It was also not possible to impose a standardised definition of sex work as an inclusion criterion in the review, since the definition varied widely and the possibility that some studies sampled women no longer engaging in sex work cannot be excluded. It is also likely that the use of TLS or RDS with a focus on recruiting street SWs may results in over-representation of FSWs who inject drugs in the East, which may inflate the national HIV prevalence estimates used in the ecological analysis. Multivariate analyses examined HIV and STIs as outcomes, with some studies using composite measures of HIV and STIs. ${ }^{22} 283035$ These were included despite different STIs varying in transmission dynamics and lengths of infectivity to examine measures of vulnerability. The paucity of data on HIV prevalence meant that we had to include studies with small sample sizes (France, Macedonia, Sweden, Croatia and Israel) in order to increase the number of countries included in the ecological analysis creating variation in the reliability of national-level HIV estimates. The ecological analysis is further limited in that we cannot infer causality or relationships on an individual level. The descriptive linear nature of the relationships we examined are unlikely to be a true representation of complex, multilevel relationships and the small number of country reports prevented multivariate analysis adjusting for potential confounders is a further limitation.

\section{CONCLUSIONS}

In Europe, HIV vulnerability among FSWs links primarily to drug injecting. There is a particular need to monitor prevalence and risk among FSWs who also inject drugs, but not to the exclusion of focusing on the potential for sexual HIV transmission. We find that published epidemiological research lacks explicit focus in delineating structural risk factors potentially indirectly linked to HIV among FSWs, and note the need to better develop such measures. There is a similar tendency regarding research investigating HIV risk factors among PWID. ${ }^{2}$ Our review thus reiterates the need for improving the extent to which epidemiological studies seek to develop measures 
of social and structural context. Researching the delineation of causal pathways to HIV transmission demands a shift from binary epidemiological models of simple 'cause and effect' to 'multilevel' models, which emphasise HIV as an outcome of multiple contributing factors interacting together. ${ }^{19}$

While interventions and research tend to envisage the health of SWs narrowly in relation to HIV and STIs, our findings show the salience of broader occupational and personal health concerns, including addressing low levels of condom and contraceptive use with non-paying partners and vulnerability to multiple forms of violence especially among FSWs who inject drugs. Public health surveillance systems should be oriented towards monitoring indicators of social context that mediate risk of HIV among FSWs. Targeted HIV interventions should be embedded inside structural interventions that simultaneously address the social welfare of SWs and their social determinants of health to create a supportive environment that facilitates the safer practice of sex work and encourages positive health behaviours.

Contributors LP, TR and VH developed the methodology for the systematic review. LP, AL and VH reviewed the collected literature. LP and VH extracted the data. LR and EJ collated the structural indicators. LP and EJ conducted the data analysis. LP interpreted the data and drafted the manuscript. All authors reviewed the manuscript and commented on the data and interpretation. All authors gave approval for the manuscript to be submitted.

Funding This review was undertaken as part of a larger project funded by the World Bank to review HIV in vulnerable populations in Europe, grant number 7153690.

Competing interests None.

Provenance and peer review Not commissioned; externally peer reviewed.

Data sharing statement No additional data are available.

Open Access This is an Open Access article distributed in accordance with the Creative Commons Attribution Non Commercial (CC BY-NC 3.0) license, which permits others to distribute, remix, adapt, build upon this work noncommercially, and license their derivative works on different terms, provided the original work is properly cited and the use is non-commercial. See: http:// creativecommons.org/licenses/by-nc/3.0/

\section{REFERENCES}

1. UNAIDS. Global Report. UNAIDS report on the global AIDS epidemic 2012. http://www.unaids.org/en/media/unaids/ contentassets/documents/epidemiology/2012/gr2012/20121120_ UNAIDS_Global_Report_2012_en.pdf

2. Jolley $\mathrm{E}$, Rhodes T, Platt L, et al. HIV among people who inject drugs in Central and Eastern Europe and Central Asia: a systematic review with implications for policy. BMJ Open 2012;2:e001465. doi:10.1136/bmjopen-2012-00146.

3. European Centre for Disease Prevention and Control/WHO Regional Office for Europe. HIV/AIDS surveillance in Europe 2010. Stockholm: European Centre for Disease Prevention and Control, 2011.

4. Burchell AN, Calzavara LM, Orekhovsky V, et al. Characterization of an emerging heterosexual HIV epidemic in Russia. Sex Transm Dis 2008;35:807-13.

5. Baral S, Beyrer C, Muessig K, et al. Burden of HIV among female sex workers in low-income and middle-income countries: a systematic review and meta-analysis. Lancet Infect Dis 2012;12:538-49.

6. Talbott JR. Size matters: the number of prostitutes and the global HIV/AIDS pandemic. PLOS ONE 2007;2:e543

7. European Centre for Disease Prevention and Control. Mapping of HIV/STI behavioural surveillance in Europe. Stockholm: European Centre for Disease Prevention and Control, 2009.
8. European Centre for Disease Prevention and Control. Implementing the Dublin declaration on partnership to fight HIVIAIDS in Europe and Central Asia: 2010 progress report. Stockholm: ECDC, 2010.

9. European Centre for Disease Prevention and Control/WHO Regional Office for Europe. HIVIAIDS surveillance in Europe 2011. Stockholm: European Centre for Disease Prevention and Control, 2012.

10. Shakarishvili A, Dubovskaya LK, Zohrabyan LS, et al. Sex work, drug use, HIV infection, and spread of sexually transmitted infections in Moscow, Russian Federation. Lancet 2005;366:57-9.

11. Cusick L. Widening the harm reduction agenda: from drug use to sex work. Int J Drug Policy 2006;17:3-11.

12. Rekart ML. Sex-work harm reduction. Lancet 2005;366:2123-34.

13. Rhodes $T$, Singer M, Bourgois $P$, et al. The social structural production of HIV risk among injecting drug users. Soc Sci Med 2005;61:1026-44.

14. Shannon K, Kerr T, Strathdee SA, et al. Prevalence and structural correlates of gender based violence among a prospective cohort of female sex workers. BMJ 2009;339:b2939.

15. Boyle FM, Dunne MP, Najman JM, et al. Psychological distress among female sex workers. Aust $N Z J$ Public Health 1997;21:643-6.

16. Romans SE, Potter K, Martin J, et al. The mental and physical health of female sex workers: a comparative study. Aust $N Z J$ Psychiatry 2001;35:75-80.

17. Seib C, Fischer J, Najman JM. The health of female sex workers from three industry sectors in Queensland, Australia. Soc Sci Med 2009;68:473-8.

18. Strathdee SA, Hallett TB, Bobrova N, et al. HIV and risk environment for injecting drug users: the past, present, and future. Lancet 2010;376:268-84.

19. Strathdee SA, Lozada R, Martinez G, et al. Social and structural factors associated with HIV infection among female sex workers who inject drugs in the Mexico-US border region. PLOS ONE 2011;6:e19048.

20. Diez Roux AV, Auchincloss $\mathrm{AH}$. Understanding the social determinants of behaviours: can new methods help? Int J Drug Policy 2009;20:227-9.

21. Liberati A, Altman DG, Tetzlaff J, et al. The PRISMA statement for reporting systematic reviews and meta-analyses of studies that evaluate health care interventions: explanation and elaboration. $J$ Clin Epidemiol 2009;62:e1-34.

22. Platt L, Grenfell P, Bonell C, et al. Risk of sexually transmitted infections and violence among indoor-working female sex workers in London: the effect of migration from Eastern Europe. Sex Transm Infect 2011;87:377-84.

23. Drain PK, Smith JS, Hughes JP, et al. Correlates of national HIV seroprevalence: an ecologic analysis of 122 developing countries. J Acquir Immune Defic Syndr 2004;35:407-20.

24. Parkhurst JO. Understanding the correlations between wealth, poverty and human immunodeficiency virus infection in African countries. Bull World Health Organ 2010;88:519-26.

25. Walmsley R. World prison population list. 7th edn. International Centre for Prison Studies, 2009.

26. Belza MJ. Prevalence of HIV, HTLV-I and HTLV-II among female sex workers in Spain, 2000-2001. Eur J Epidemiol 2004;19:279-82.

27. Cwikel JG, Lazer T, Press $\mathrm{F}$, et al. Sexually transmissible infections among illegal female sex workers in Israel. Sex Health 2006;3:301-3.

28. Folch C, Esteve A, Sanclemente C, et al. Prevalence of human immunodeficiency virus, Chlamydia trachomatis, and Neisseria gonorrhoeae and risk factors for sexually transmitted infections among immigrant female sex workers in Catalonia, Spain. Sex Transm Dis 2008;35:178-83.

29. Gutierrez M, Tajada P, Alvarez A, et al. Prevalence of HIV-1 non-B subtypes, syphilis, HTLV, and hepatitis $B$ and $C$ viruses among immigrant sex workers in Madrid, Spain. J Med Virol 2004;74:521-7.

30. Linhart Y, Shohat T, Amitai Z, et al. Sexually transmitted infections among brothel-based sex workers in Tel-Aviv area, Israel: high prevalence of pharyngeal gonorrhoea. Int J STD AIDS 2008;19:656-9.

31. Nigro L, Larocca L, Celesia BM, et al. Prevalence of HIV and other sexually transmitted diseases among Colombian and Dominican female sex workers living in Catania, eastern Sicily. J Immigr Minor Health 2006;8:319-23.

32. Papadogeorgaki $\mathrm{H}$, Caroni $\mathrm{C}$, Frangouli $\mathrm{E}$, et al. Prevalence of sexually transmitted infections in female sex workers in Athens, Greece-2005. Eur J Dermatol 2006;16:662-5.

33. Vall-Mayans M, Villa M, Saravanya M, et al. Sexually transmitted Chlamydia trachomatis, Neisseria gonorrhoeae, and HIV-1 
infections in two at-risk populations in Barcelona: female street prostitutes and STI clinic attendees. Int $J$ Infect Dis 2007;11:115-22.

34. EuroHIV. HIVIAIDS Surveillance in Europe. Saint-Maurice: French Institute for Public Health Surveillance; 2007, Mid-year report 2006.

35. Nielsen S, Haar K, Sailer A, et al. STI rates and risk factors among female sex workers attending STI testing sites in Germany. Quebec: International Society for Sexually Transmitted Disease Research, 10-13 July 2011.

36. Day S, Ward H. Approaching health through the prism of stigma: research in seven European countries. In: Sex work, mobility and health in Europe. London: Kegan Paul Limited, 2004:139-61.

37. Ola TM, Wiwoloku V. HIV prevalence, AIDS knowledge and sexual behaviour among female migrant sex workers in Palermo, Italy. XVIII International AIDS Conference; 18-23 July, Vienna, Austria, 2010.

38. van Veen MG, Gotz HM, van Leeuwen PA, et al. HIV and sexual risk behavior among commercial sex workers in the Netherlands. Arch Sex Behav 2010;39:714-23.

39. Bruckova M, Bautista CT, Graham RR, et al. HIV infection among commercial sex workers and injecting drug users in the Czech Republic. Am J Trop Med Hyg 2006;75:1017-20.

40. Country Coordination Committee Republic of Kazakhstan. UNGASS 2010 country progress report. Almaty, Republic of Kazakhstan: Ministry of Health, 2010.

41. Family Health International. 2006 Behavioural and biological surveillance study. Kosova: Family Health International, 2007.

42. Gjenero-Margan I, Kolaric B. Epidemiology of HIV infection and AIDS in Croatia-an overview. Coll Antropol 2006;30:11-16.

43. Ilic D, Šipetić S, Bjegović V. Risk of HIV infection among indoor and street sex workers and their use of health services in Belgrade Serbia. Srp Arh Celok Lek 2010:219-24.

44. UNGASS. UNGASS Country Progress Report: Republic of Macedonia 2010 January 2008-December 2009. Report No.

45. UNGASS. UNGASS Country Progress Report: Bosnia and Herzegovina 2010 January 2008-December 2009. Report No.

46. Suleymanova J, Gadirova H, Khasiyev S. Seroepidemiological research of HIV, hepatitis $B, C$, syphilis and behavioural risk factors among most-at-risk gropus in Azerbaijan. XVIII International AIDS Conference; 18-23 July, Vienna, Austria, 2010.

47. Smolskaya TT, Yakovleva AA, Kasumov VK, et al. HIV Sentinel Surveillance in High-Risk Groups in Azerbaijan, Republic of Moldova and in the Russian Federation World Health Organization 2004.

48. Uuskula A, Fischer K, Raudne R, et al. A study on HIV and hepatitis $C$ virus among commercial sex workers in Tallinn. Sex Transm Infect 2008;84:189-91.

49. Tsereteli N, Lomidze G. Low HIV prevalence among female sex workers in two cities of Georgia-contributing factors. XVIII International AIDS Conference; 18-23 July, Vienna, Austria, 2010.

50. National report on the implementation of the declaration of commitment on HIV/AIDS vilnius. Lithuania: 2010.

51. Republic of Belarus: National Report on the Implementation of the Declaration of Commitment on HIV/AIDS Minsk, Belarus: 2010 January 2008-December 2009. Report No.

52. Country Report of the Russian Federation on the Implementation of the Declaration of Commitment on HIV/AIDS 2008 January 2006December 2007. Report No.

53. International AIDS Alliance. Behavioural monitoring and HIV infection prevalence among female sex workers as a component of second generation surveillance 2009

54. Rhodes T, Platt L, Maximova S, et al. Prevalence of HIV, hepatitis $\mathrm{C}$ and syphilis among injecting drug users in Russia: multi-city study. Addiction 2006;101:252-66.

55. Lomax $\mathrm{N}$, Wheeler $\mathrm{H}$, Anaraki $\mathrm{S}$, et al. Management of a syphilis outbreak in street sex workers in east London. Sex Transm Infect 2006;82:437-8.

56. EuroHIV. HIVIAIDS Surveillance in Europe. Saint-Maurice: Institut de veille sanitaire; 2006, Mid-year report 2005.

57. D'Antuono A, Andalo F, Carla EM, et al. Prevalence of STDs and HIV infection among immigrant sex workers attending an STD centre in Bologna, Italy. Sex Transm Infect 2001;77:220.

58. Spizzichino L, Zaccarelli M, Venezia S, et al. HIV infection among immigrant sex workers in Rome: comparing men, women and transgenders. XVII International AIDS Conference; 3-8 August, Mexico city, Mexico, 2008.

59. Ward H, Day S. What happens to women who sell sex? Report of a unique occupational cohort. Sex Transm Infect 2006;82:413-17.

60. Belza MJ, Group EVS. Risk of HIV infection among male sex workers in Spain. Sex Transm Infect 2005;81:85-8.
61. Creighton S, Tariq S, Perry G. Sexually transmitted infections among UK street-based sex workers. Sex Transm Infect 2008

62. EuroHIV. Report on the EuroHIV 2006 survey on HIV and AIDS surveillance in the WHO European Region. Saint-Maurice: Institut de veille sanitaire, 2007

63. UNGASS. Country Progress Report on Monitoring the Declaration of Committment on HIV/AIDS: Republic of Bulgaria 2010 January 2008-December 2009. Report No.

64. Bruckova M, Bautista CT, Graham RR, et al. Short report: HIV infection among commercial sex workers and injecting drug users in the Czech Republic. Am J Trop Med Hyg 2006;75:1017-20.

65. UNGASS. UNGASS Country Progress Report: Montenegro 2010 January 2008-December 2009. Report No.

66. Ministry of Health. Research among populations at higher risk to HIV and among people living with HIV/AIDS. Basic results of surveillance research 2009-2010. Ministry of Health, Belgrade, Republic of Serbia 2010.

67. Family Health International (FHI). Serbia-Behavioral and Biological Surveillance Study Report 2006.

68. ICON Institute for Public Health. Operational Research on key STIs and HIV in Turkey Ankara: 2007.

69. Qyra ST, Basho M, Bani R, et al. Behavioral risk factors and prevalence of HIV and other STIs among female sex workers in Tirana, Albania. New Microbiol 2011;34:105-8.

70. UNGASS. UNGASS Country Progress Report: Republic of Armenia 2010 January 2008-December 2009. Report No.

71. UNGASS. Country Progress Report: Republic of Armenia 2008 January 2006-December 2007. Report No.

72. UNGASS. UNGASS Belarus 2010 country progress report. 2010.

73. Dershem L, Tabatadze M, Tsereteli N, et al. Characteristics, high-risk behaviors and knowledge of STI/HIV/AIDS, and STI / HIV prevalence of street-based female sex workers in Tblisi, Georgia: 2004-2006. Report on three behavioral surveillance surveys with a biomarker component for the SHIP Project Save the Children 2007.

74. UNGASS. UNGASS 2010 Country Progress Report: Lithuania.

75. UNGASS. UNGASS Country Progress Report: Republic of Moldova Chisinau: 2010 January 2008-December 2009. Report No.

76. Platt L, Rhodes T, Lowndes CM, et al. The impact of gender and sex work on sexual and injecting risk behaviours and their association with HIV positivity amongst injecting drug users in an HIV epidemic in Togliatti City, Russian Federation. Sex Transm Dis 2005;32:605-12.

77. Country Report of the Russian Federation on the Implentation of the Declaration of Committment on HIV/AIDS 2008 January 2006-December 2007. Report No.

78. Federal Service for Surveillance of Consumer Rights Protection and Human Well-Being Ministry of Health and Social Development of the Russian Federation. Country Progress Report of the Russian Federation on the Implementation of the Declaration of Commitment on HIV/AIDS Moscow: 2010.

79. UNGASS. National Report on Monitoring Progress Towards the UNGASS Declaration of Commitment on HIV/AIDS: Ukraine Kyiv: 2010 January 2008-December 2009. Report No.

80. Pohorila N, Taran Y, Kolodiy I, et al. Behavior monitoring and HIV-infection prevalence among injection drug users Kyiv: ICF "International HIV/AIDS Alliance in Ukraine" 2010.

81. Ongoeva D. HIV-infection epidemiolgical analysis among sex workers in Central Asia. Kyrgystan: Oblast AIDS Centre, 2010

82. Todd CS, Khakimov MM, Giyasova GM, et al. Prevalence and factors associated with human immunodeficiency virus infection among sex workers in Samarkand, Uzbekistan. Sex Transm Dis 2009;36:70-2.

83. Todd CS, Khakimov MM, Alibayeva G, et al. Prevalence and correlates of human immunodeficiency virus infection among female sex workers in Tashkent, Uzbekistan. Sex Transm Dis 2006;33:496-501.

84. Kolemasova S. Review of HIV prevention and risk factors associated with HIV infection among sex workers in Uzbekistan. XVIII International AIDS Conference; 18-23 July, Vienna, Austria, 2010.

85. Platt L, Rhodes $\mathrm{T}$, Judd A, et al. Effects of sex work on the prevalence of syphilis among injection drug users in 3 Russian cities. Am J Public Health 2007;97:478-85.

86. Mak RP, Van Renterghem L, Traen A. Chlamydia trachomatis in female sex workers in Belgium: 1998-2003. Sex Transm Infect 2005;81:89-90.

87. Matteelli A, Beltrame A, Carvalho AC, et al. Chlamydia trachomatis genital infection in migrant female sex workers in ltaly. Int J STD AIDS 2003;14:591-5. 
88. Sirmatel F, Sahin N, Sirmatel O, et al. Chlamydia trachomatis antigen positivity in women in risk groups and its relationship with the use of antibiotics. Jpn J Infect Dis 2005;58:41-3.

89. Markosyan KM, Babikian T, DiClemente RJ, et al. Correlates of HIV risk and preventive behaviors in Armenian female sex workers. AIDS Behav 2007;11:325-34.

90. UNFPA, UNICEF. Consultation on strategic information and HIV prevention among most-at-risk adolescents: Research Tool-kit 2009.

91. Poon AN, Li Z, Wang N, et al. Review of HIV and other sexually transmitted infections among female sex workers in China. AIDS Care 2011;23(Suppl 1):5-25.

92. Kral $A H$, Bluthenthal RN, Lorvick J, et al. Sexual transmission of HIV-1 among injection drug users in San Francisco, USA: risk-factor analysis. Lancet 2001;357:1397-401.

93. Wood E, Schachar J, Li K, et al. Sex trade involvement is associated with elevated HIV incidence among injection drug users in Vancouver. Addict Res Theory 2007;15:321-5.

94. The UK Collaborative Group for HIV and STI Surveillance. Testing times. HIV and other sexually transmitted infections in the United Kingdom. London: Health Protection Agency, Centre for Infections, 2007.

95. Rhodes T, Simic M, Baros S, et al. Police violence and sexual risk among female and transvestite sex workers in Serbia: qualitative study. BMJ 2008;337:a811.

96. Shannon K, Strathdee SA, Shoveller J, et al. Structural and environmental barriers to condom use negotiation with clients among female sex workers: implications for HIV-prevention strategies and policy. Am J Public Health 2009;99:659-65.

97. Watts C, Zimmerman C. Violence against women: global scope and magnitude. Lancet 2002;359:1232-7.

98. Shannon K, Rusch M, Shoveller J, et al. Mapping violence and policing as an environmental-structural barrier to health service and syringe availability among substance-using women in street-level sex work. Int J Drug Policy 2008;19:140-7.

99. Boynton $\mathrm{P}$, Cusick L. Sex workers to pay the price. BMJ 2006;332:190-1.

100. Church S, Henderson M, Barnard M, et al. Violence by clients towards female prostitutes in different work setting: questionnaire survey. BMJ 2001;322:524-5

101. Campbell R, Storr M. Challenging the Kerb Crawler Rehabilitation Programme. Feminist Rev 2001;67:94-108.

102. Kinnell H. Violence and sex work in Britain. Cullompton: Willan Publishing, 2008:81-92.

103. Hammett TM, Harmon MP, Rhodes W, et al. The burden of infectious disease among inmates and releases from US correctional facilities, 1997. Am J Public Health 2002:92:1789-94.

104. Stern V. Problems in prisons worldwide, with a particular focus on Russia. Ann N Y Acad Sci 2001;953b:113-19.

105. Cusick L, Kinnell H, Brooks-Gordon B, et al. Wild guesses and conflated meanings? Estimating the size of the sex worker population in Britain. Crit Soc Pol 2009;29:703-19.

106. Wilkinson R, Pickett K. The spirit level. Why more equal societies almost always do better. London: Penguin Group, 2009.

107. United Nations Development Programme (UNDP). Human Development Report 2009: Overcoming barriers: Human mobility and development New York: Human Development Report 2009: Overcoming barriers: Human mobility and development 2009.

108. Shahmanesh M, Patel V, Mabey D, et al. Effectiveness of interventions for the prevention of HIV and other sexually transmitted infections in female sex workers in resource poor setting: a systematic review. Trop Med Int Health 2008;13:659-79.

109. Strathdee SA, Sherman SG. The role of sexual transmission of HIV infection among injection and non-injection drug users. J Urban Health 2003:S7-14. 